\title{
Reflections on developing an offshore, action research/learning-based PhD program
}

Shankar Sankaran, Associate Professor, Graduate College of Management, Southern Cross University, Australia

Stewart Hase, Associate Professor, Graduate College of Management, Southern Cross University, Australia

Bob Dick, Adjunct Professor, Southern Cross University, Australia

Alan Davies, Emeritus Professor, Southern Cross University, Australia

\begin{abstract}
In this paper the authors describe their experience of establishing an action research/learning-based doctoral program in Singapore by an Australian university, which was designed to help managers get academic accreditation while solving workplace problems. The program was designed by four managers working in Singapore and their supervisors. These managers had completed a PhD program using action learning/action research in their workplace under the supervision of Australian academics. The paper describes the various challenges faced by the candidates, supervisors and administrators in developing and implementing the new program.
\end{abstract}

Keywords: action-oriented methodologies; action learning; action research; doctoral programs; management learning; workplace learning

\section{Introduction}

The action research $\mathrm{PhD}$ program described in this paper arose out of the experiences of four managers who had themselves completed a PhD program started by another Australian university (Uni A) in Singapore in 1994. Uni A's program encouraged the candidates to use action research to address workplace issues as their thematic concern.

A PhD by distance education was a relatively novel idea at that time in Singapore, since most offshore postgraduate programs offered in the country were at the Masters level. Doctoral candidates usually undertook their research at one of the two Singapore universities, where opportunities were limited (Yee 1995, 74-77), or went overseas. However, the divide between theory and practice was being bridged through innovative doctoral programs devoted to the development of practitioner-scholars, such as the one started in Singapore by Uni A.

This paper's premise is that 'action-oriented methodologies' provide useful tools for management research. The authors consider action learning, action research and action science to be a group of interrelated 'action-oriented methodologies' that work well together.

The following account of the experience of developing a research program relevant to practitioners is written up as an action learning/action research project. Thus several cycles of action and reflection are described that demonstrate how the program evolved.

\section{Cycle 1: The Uni A program}

Although the idea of using the workplace as a research setting appealed to the candidates in Uni A's program, they struggled with the concept of action research. Managers in Singapore, at that time, were used to applying structured solutions from Japan (such as Kaizen and Hoshin) or the West (such as the Kepner-Tregoe method and Management by Objectives) in their organisation's training and development programs. They found it difficult to grasp how an evolving participatory research methodology could be applied in their workplace given its lack of obvious structure.

\section{A search conference}

The candidates were encouraged to use the 'search conference' as a way of 'unfreezing' their assumptions before introducing action learning/action research in their workplace. Professor Alan Davies conducted a search conference for the candidates, with 'global management trends' as the context and 'the challenge of completing a $\mathrm{PhD}$ in three years using real-time problem solving in the workplace as an action research opportunity' as the focal question.

Davies found that high levels of public (i.e. workshop) obedience and conformity had made the search conference process highly unsettling and challenging deep-seated norms. The managers saw the Professor as the expert, and were unsure of how to proceed when they were divided into self-managed 
groups and were expected to come up with answers. The processes used in the conference were an excellent introduction to the ambiguities inherent in action research. It forced the managers out of their comfort zones and into thinking about alternative ways of tackling their research questions.

One of the most important outcomes of the search conference, in terms of developing a sustainable model for $\mathrm{PhD}$ supervision, was that the candidates formed peer groups based on common interests to determine their research focus and develop their research proposal. Initially the groups met just as any other group until one of the candidates, Shankar Sankaran, introduced action learning to his group as he was planning to use it in his organisation. This group of six candidates, who were all being supervised by Davies, decided to adopt an action learning format for its meetings (McGill and Beatty, 1995; Pedler, 1997) and began to call itself a 'learning set'. At each meeting one of the set members would present a problem concerning their research and the others would ask 'insightful' questions to help the candidate 'peel the onion' and think outside the square to find a solution. Sometimes a set member would present material that could be of use to the others, such as a research tool. This was similar to the 'programmed instruction' used in action learning. Initially, Sankaran acted as the 'set adviser'. However, as the set evolved it became self-facilitating.

\section{Supervision}

The six candidates assigned to Davies for supervision adopted Bob Dick's (2002) model of action research, as it was not prescriptive but had the versatility to draw on a variety of approaches, such as action learning, action science and grounded theory, while still maintaining rigour. This came about because Davies had requested Dick to co-supervise the candidates because of his reputation as an action researcher. This was an important step because it recognised that having multiple supervisors, who brought different strengths to the candidate's research, is a key contributor to the success of the program. This is more akin to the way in which American doctoral students are supervised compared to the English and Australian models.

The candidates and supervisors jointly developed a process of engagement during the annual supervision sessions in Singapore, which combined group and individual forms of supervision. Each session lasted five days and was organised along the following lines:

- A start-up meeting involving all the candidates covering peer group status reporting and planning.

- Individual sessions, where other candidates could participate as observers and idea generators.

- A closing, reflection session with all the candidates, at which clearly defined milestones were negotiated for achievement before the next meeting.

The six candidates in this group, at their own initiative, decided to meet monthly, or as the situation demanded, to question and reflect with each other and share resources. The candidates, who were fulltime professionals, had to depend on one another to minimise the time required to get the necessary resources to support their research. They used an action-learning format for their meetings, and all outcomes of the 'learning sets' were emailed to the supervisors for comment. These notes served as useful data when it came to reflecting on the experience. This mutual support proved critical in overcoming the ebb and flow of enthusiasm that is part of any long research endeavour and we believe contributed to the success rate of the group, which was higher than that of all the other groups. Four of the original six members completed their doctorates at the same time. The two who withdrew from the program did so due to other priorities in their lives.

\section{Reflection}

- The ethics approval process delayed progress for all the candidates for several months. The ethics approval procedure was derived from medical research, which involved a different set of circumstances to those faced by action researchers tackling organisational development and research challenges. Candidates did not know how to complete the forms and, when they attempted to do so, they did not meet the requirements of the ethics committee. The local agent of Uni A was of no help. The two supervisors assumed responsibility for resolving this issue by writing a letter directly to Uni A's ethics committee. Although Uni A granted a six-month extension to the candidates, valuable time was wasted and unnecessary stress created.

- Although action research is designed to deliver management (or action) outcomes as well as research outcomes, the candidates found it difficult to distil their research objectives from their more obvious management objectives. Davies found a way to change the thinking of the managers 
by using a diagram that showed 'actions' generally produced 'management outcomes' while 'reflections’ produced 'research outcomes' as shown in Figure 1

Insert Figure 1 about here.

- As the entire program was held offshore in Singapore, it was difficult for the candidates to identify with Uni A in Australia. After the initial seminars, meetings with Uni A staff were infrequent. Although the candidates were given a VIP treatment by Uni A at their graduation, this face-to-face contact with staff of Uni A came much too late. While the candidates were in regular contact with their own supervisors, they were only adjunct staff of Uni A. This led to the candidates building a closer relationship with their supervisors’ home university, Southern Cross University (SCU).

- The academic English in which the theses had to be written posed a problem to some of the candidates, whose medium of education had been Chinese. Writing and editing the theses was time consuming for both candidates and supervisors.

- $\quad$ Some of the candidates who were engineers were used to expressing their ideas in diagrams rather than words and one was used to writing one-page reports in his Japanese company. One candidate was helped to transform his diagrams into words by getting him to talk the others through them and tape recording his explanations. These recordings became the basis for his writing. Dick encouraged another candidate suffering from writer's block to start recording his reflections as emails to himself (as the candidate was found to respond to emails quickly). The candidate wrote up his reflections as a series of emails from his office email to his home email, and these became the 'reflective memos' of his data analysis. (Sankaran 1997)

- The Action Research and Evaluation On-Line (AREOL) course conducted by Dick brought some of the candidates in contact with action researchers in Australia and New Zealand. AREOL was a vital educational tool for participants that, again, came about as a result of the supervisors' initiative rather than as a part of Uni A's doctoral program. It also built links with the Action Learning, Action Research and Process Management Association of Australia (ALARPM). A joint conference on action research was organised in Singapore by the candidates in conjunction with ALARPM and the Singapore Institute of Management (SIM). This helped legitimate the use of action research in management development in Singapore. It helped that SIM was also promoting an action learning-based Master of Business (MBA) program at the time.

- The candidates were able to network with action researchers around the world, through an electronic discussion list managed by Dick, called 'arlist'. This exposure to an international audience was valuable. The candidates who worked in competitive environments in Singapore found the generosity of experienced action researchers and action learners a pleasant surprise. Sankaran remembers fondly the letters of encouragement he received from luminaries such as Reg Revans and William Foote-Whyte.

- The fact that the candidates came from different organisational cultures enabled them to draw out relevant knowledge from one another's fields. Some candidates also helped others with the content area of their research which helped to reduce the supervisors' workload, so that they could focus on the research process and help the candidates extract their research outcomes. For example, when one candidate, an engineer, had difficulties understanding content analysis, what helped him was the process used in applying grounded theory found in nursing literature sent to him by another candidate who was working with nurses.

- $\quad$ Finding suitable examiners who were supportive of action research and the personal writing style of some of the candidates was difficult. The supervisors had to rely on the candidates to find suitable content examiners for their research projects. The examiners' reports reflected some concerns about the use of action research which was anticipated by the supervisors. However, this did not prove to be a major hurdle as the comments were defended to the satisfaction of the University.

\section{Cycle 2: The new program}

The four managers who successfully completed their theses with Uni A and their supervisors felt that they had managed to put together the foundations of a successful process using action learning as a catalyst for completing a PhD on deadline. However, based on their experience, they felt that the program could be improved further. Since Uni A had already established a close relationship with a 
local provider in Singapore, it would be difficult to get it to modify its program. At the time, Uni A and its local provider were looking at a 'mass' market, enrolling close to 50 candidates spread over two intakes a year. The four managers felt that it would be better to enrol smaller groups of candidates and work with them effectively to achieve a good completion rate in a short time. They felt that candidates in Singapore would not mind the higher cost entailed by the smaller intakes, so long as the success rate was good. This made them approach SCU with a proposal for a better-designed PhD program, targeting a smaller group of researchers. SCU's vice-chancellor accepted their proposal.

\section{Program features}

Some of the processes that had worked well in Uni A's program were retained, and others added.

Items that were retained included:

- Use of email for regular contact with supervisors

- Participation in mailing lists devoted to action learning and action research

- The 'learning set' structure of action learning.

- Peer collaboration and cross-functional learning, by forming learning sets of managers from different disciplines/industries

- Using action research flexibly

- $\quad$ Scheduled face-to-face meetings of the learning set with the supervisors.

Items that were added included:

- Using Action Research and Evaluation Online as a preparatory program for all candidates who joined the program, irrespective of their research background, so that they became familiar with action research methodology.

- A residential seminar at SCU at the beginning of the program, which used a search conference format to focus on completing the $\mathrm{PhD}$ in three years. This seminar was designed to:

- $\quad$ Build face-to-face contact and rapport with the university early in the program

- $\quad$ Enhance the participatory nature of the approach to be used

- 'Thaw out' candidates by confronting them with more qualitative approaches to research

- $\quad$ Develop personal ownership of the candidates' research

- Develop candidates' capacity to report on their work in front of peers

- $\quad$ Shorten the time taken to submit a research proposal by producing a favourable academic environment outside the workplace

- $\quad$ Complete the human research ethics applications with their supervisors to expedite data collection.

- Using the four managers who were involved in the original program as co-supervisors for the next group of candidates in Singapore. These co-supervisors would facilitate the monthly meetings of the 'learning set', and would be available at other times when candidates needed help.

\section{Problems faced at SCU}

The use of action methodologies in management research was new to many in SCU. Hence there were issues about initial acceptance for this form of doctoral program from the university's research committee. Most managers who entered this program had an MBA or a Master of Engineering rather than honours degrees. This caused delays in interpreting the research experience of the candidates, and hence in offering them admission. A research qualifier program had to be designed for these candidates.

Associate Professor Stewart Hase, who was more familiar with the admission procedures at SCU, helped Davies to convince the Head of the Graduate Research College, Professor Peter Baverstock, a scientist by background, that it was worthwhile supporting this new PhD program. Davies and Hase worked out how to use Action Research and Evaluation Online as a qualifier for practitioners who wish to do action research for academic purposes. Hase later became one of the supervisors for the program.

The new program begins

Eventually, the new program, with four new candidates based in Singapore, was launched in 1999. A new organisation, called Management Learning and Action Research (MaLAR), was established by the four managers in Singapore to run the program. At the end of 1999, Sankaran joined SCU as an academic and had to resign from his directorship of MaLAR, to avoid any conflict of interest. 
However, he was appointed SCU's academic coordinator of the program, and thus the program found a committed champion at the university.

Three of the four candidates who joined the program in 1999 have successfully graduated. Two candidates who enrolled in 2000 have also completed. Eight more candidates are in various stages of completion.

\section{Difficulties encountered by the program}

The Graduate College of Management, which was the program's academic home in SCU, had an agent in Singapore for its MBA and Doctor of Business Administration (DBA) program. Students graduating from its MBA program often progressed to the DBA program. Hence MaLAR found it difficult to recruit candidates from SCU's MBA graduates. The fees for the MaLAR program was also high compared to other $\mathrm{PhD}$ programs in Singapore, and candidates were concerned about completion.

SCU, which is a regional university, is not well known outside Australia even though it is a government accredited university and enjoys a good reputation in its home market. Thus the program, which was based on recruiting 6-8 candidates a year to be economically viable failed to meet its target. While four candidates were recruited quickly through personal contacts, promoting it in the wider market proved difficult. Besides, there were no actual results as yet to show that the $\mathrm{PhD}$ could be completed in three years. The low intake also did not make it economically viable for MaLAR to employ an administrator or marketing staff.

MaLAR managed to secure an action research certification program through another Australian university (Uni B) to increase its income, but this initiative was killed by Uni B's local agent (for its other programs), which viewed MaLAR as a prospective competitor.

The number of candidates increased slowly but GCM's management started questioning the financial viability of the program.

\section{Reflection}

- The program was academically successful as the candidates who joined it were progressing well. Only one dropped out but this was due to personal reasons. The high success rate can be attributed, the authors believe, to Dick's (AREOL 2006) concept of action research which advocates that in action research the emphasis could be on 'action' or 'research' as the situation demands. This flexible approach helped the managers who were enrolled in the program to achieve organizational change that required an emphasis on action in their research. (briefly explain what you mean by this)

- Marketing an innovative and non-mainstream program such as this is difficult in a conservative climate that existed at that time in Singapore, despite the fact that it delivers real organisational outcomes as well as a high-level qualification (why do you think this is?).

- While SCU saw it as a well organised program that contributed to the strength of action research as a developing area of research strength, the Graduate College of Management questioned its economic viability. Thus, there is a tension between innovative academic practice and the need to make money that is difficult to reconcile.

- Innovations and paradigm busters rely on champions who are able to manoeuvre around the various obstacles that organisations inevitably present. Sankaran and Hase secured some commercial projects with organisations to use action learning/research to show the university that these have commercial potential and that the program in Singapore would actually help enhance the university's reputation in offering such programs to industry.

- Learning was not confined to the formal content of the research program. In fact, the real learning involved significant attitudinal shifts on the part of candidates that had to do with process rather than content.

\section{Cycle 3: Growth}

MaLAR and the Graduate College of Management discussed how they could improve the numbers. As a result, in 2003, a Master's program using action learning and action research was introduced in Singapore so that candidates could either graduate with a Masters qualification or articulate to a $\mathrm{PhD}$ program. This helped to reduce the barriers to entry due to the fees and research qualifications. This move has paid off and resulted in more candidates joining the program in 2004. 
MaLAR changed its name to Southern Cross Professional Institute International (SCPii) to promote the university's name. It has started working with a firm called Edu Outdoor Activities to promote action learning in Singapore. SCPii has also recently introduced action research to school teachers in the country. Thus SCPii is showing signs of becoming a centre for action research in Singapore.

In accord with Australian government legislation that requires universities to identify areas of research strength a College of Action Research was approved by SCU. This has provided legitimacy to action research in a previously hostile environment.

Graduate College of Management and SCPii are also considering conducting continuing professional development programs in areas in which SCPii graduates have specialised. These diversification activities will hopefully sustain SCPii in Singapore.

\section{Cycle 4: Results}

As mentioned earlier, the key concern of this project was the scholarship-practitioner interface (this has been lost now in this version - however it is an important point \& arises in the conclusion so needs to be raised in the introduction). While the doctoral process ensured the scholarly component, it is important to recognise the outcomes that had 'real life' applications. Some of the projects carried out by the candidates include:

- Tay Boon Hou: A soft systems methodology-based diagnostic model that vastly improved the process of developing an expert system diagnostic model for a military environment.

- $\quad$ Allan Chung: A job adaptation and job management model to help people build their competencies and cope with high job mobility due to frequent restructuring of organisations.

- Eric Goh: A project cost management model and related application software that is used throughout the life cycle of a project.

- Radika Vasudev: A speech-language therapy practice model and checklist to measure the dimensions of practice through self, peer or supervisors' evaluation of skills for use by speech therapists in Singapore.

- Keith Ng: The identification of the key factors vital to principal-distributor collaboration in the context of the crane industry in Singapore, Malaysia and Indonesia.

Issues faced by the researchers

- Tay was initially a typical engineer, with very little appreciation of socio-technical issues. Being an engineer himself, Sankaran could empathise with Tay's problem and suggested that he try Checkland's (1999) soft systems methodology. This helped Tay to think conceptually about human activity systems.

- $\quad$ Chung faced a number of difficulties. He had to change jobs during the course of his research and this caused him a lot of anxiety as a migrant. Besides, both organisations he worked for did not give him permission to conduct action research. He almost gave up on his $\mathrm{PhD}$ but Dick and Hase were persistent and, in the end, Chung was able to transform his personal difficulties into a thesis on how to adapt to difficult work situations. A problem often faced by action researchers/learners is that they require organizational sponsorship for questioning the belief systems of the organization.

- Goh's thesis took a bit longer to complete. One problem was that his three examiners disagreed in their evaluations. While one of them, a well-known project management expert, felt that Goh's work was an excellent study of a real problem faced by all project managers, the other two had some reservations that his model had not been sufficiently tested. Hase and Sankaran had to explain to the university's Higher Degrees Committee that testing Goh's model would be like undertaking another $\mathrm{PhD}$ as the projects he worked on took more than three years to complete. This resulted in some discussions between his supervisor and one of the examiners over a period of time. Meanwhile, Goh managed to triangulate his findings through member checking and his thesis was passed as a result.

Making action research prominent in SCU

One of the benefits of the $\mathrm{PhD}$ program has been the establishment of action research as one of the designated developing areas of research strengths of SCU. Two action research oriented organisations have been set up in the university, the Southern Cross Institute of Action Research as well as College of Action Research. 
(suggestion - with so many abbreviations I wonder if it is easier for the reader if some of the shorter names are used in full e.g. Southern Cross University and College of Action Research rather than as abbreviations)

The Southern Cross Institute of Action Research was set up to do research or consultancy work with external organisations to earn income to support the university's action research activities. The action researchers in the university, Hase and Sankaran, have worked with Sandvik Australia, a Swedish company, to develop leaders and senior managers using action learning. Hase has worked with the Queensland mining industry on human resource development programs. The institute also organises events with ALARPM.

The College of Action Research was set up to help academics and candidates to do academic research in the university. For example, all Australian candidates who are interested in action research can enrol in a Masters or PhD program under the college. Supervisors across the university can approach the college for help in the use of action research methodology.

The Southern Cross University Press has also published books on action learning and action research (Sankaran, et al., 2001; Speedy, 2002).

Recent visits by Sankaran to the US and UK, where he met prominent action researchers, confirmed that SCU's status as a centre for action research is now recognised internationally (Sankaran 2005). If you Google 'action research', the first two or three listings are action research resources at SCU.

\section{Feedback}

A survey of current candidates revealed that there is still some room for improvement, such as the quality of feedback at learning set meetings, helping candidates to achieve better work-life balance, improving the commitment of the local supervisor to the program (they too are all busy executives) and helping candidates to publish during their research. Other issues include improving the administration of the program in Singapore, focused marketing and enhancing SCU's image to increase market share. Candidates felt that the intake was still low.

An interesting observation about the 'learning sets' in the SCPii's program was that while some candidates found the sets useful others found them threatening as some of their ideas were challenged severely at set meetings. This indicates the need for keeping an appropriate balance between 'support' and 'challenge' in an action learning set. This is being improved now with the assistance of the supervisors from the university. It was also found that some of the candidates who took longer to complete the program did not attend 'learning set' meetings regularly, emphasising the key role played by the 'learning sets' in the program. The current students are starting to realise this and attendance at set meetings has improved. Getting busy managers who travel often in South East Asia to allocate time to attend 'learning set' meetings regularly is a continuing challenge for the program.

Feedback from candidates seems to indicate that the strategies used in the program have been effective in helping them complete their doctorates in 3-4 years. One of the major problems faced by Australian universities is the poor rate of completion of doctoral programs, due to which the government has asked universities to focus on areas of research strength. This program has therefore helped support the development of action research as an area of research strength at SCU.

As a response to the feedback, a training workshop for local supervisors was conducted in 2005 to improve their capabilities. Efforts are underway to publish the candidates' research findings. Five papers have been published so far, and a special issue of the Journal of Management Development on action research, based on the work by the original four managers, is in the pipeline. The Southern Cross Institute of Action Research and SCPii are also planning to start an Asia Pacific Action Learning/Action Research Society and peer-reviewed journal. However, more work needs to be done to ensure that the program will have sustainable numbers.

\section{Quality of the research}

In order to evaluate the quality of the research done as part of this PhD program, the authors will look at the concept of first, second and third person research (Torbert, 1991; Reason, 1999). 
From a first-person perspective, 'aimed at developing an inquiring individual actor' (Reason, 1999, 222), all the candidates started questioning their own assumptions as they progressed in the program. A good example was the conversion of Tay from a pure engineering view of the problem he was addressing to a socio-technical perspective.

From a second-person perspective, where 'inquiry is focused through a group which is normally established for the purpose of collaborative learning and inquiry' (Reason, 1999, 223), the learning set structure of the program based on action learning is clear evidence of this. It is reflected in the feedback received from most of the candidates. The supervisors also felt included in second-person research as it helped them to learn about the culture of Singapore and the content areas of the candidates.

From a third-person perspective, 'aim to mobilize inquiry in a wider community or organization' (Reason, 1999, 223), the authors feel that this has happened more at the university, which has had the foresight to promote action research as an area of research strength leading to the diffusion of action research to other schools in the university. The Southern Cross Institute of Action Research has conducted in-house seminars to promote action research and organised a conference at its campus with ALARPM in 2003. It has also organised seminars when prominent action researchers visit Australia. Candidates in SCU's DBA and domestic PhD programs have also started using action research. GCM also works with industry in leadership development projects using action learning and action research.

It is hoped that when the Singapore program builds up a critical mass of action researchers a wider community in that country will also see the benefit of using action research methodologies. The climate in Singapore has changed since the four managers started their $\mathrm{PhD}$ program a decade ago. The Singapore government is actively encouraging Singaporeans to become more creative.

\section{Conclusions}

This paper has shown that although action learning and action research are gaining popularity in business research there are many difficulties to be overcome before practising managers will undertake to use them for academic accreditation. Culture is a critical issue in change management and cannot be dismissed lightly as many organisations venturing into foreign lands have discovered to their detriment. Similarly, the academic world finds it difficult to embrace new paradigms that challenge existing orthodoxies, despite the rhetoric that insists universities are centres for creativity. There are still many issues to be resolved with human research ethics approval for action methodologies by ethics committees entrenched in the positivist tradition. Researchers in universities are not well versed in a wide range of methodologies which prevents them from being able to properly evaluate new approaches such as action research. With the rapid commercialisation of the education sector, niche programs will find it hard to survive even though they may contribute to valuable research with outcomes that can be applied in practice. Recent announcements by the Australian government regarding university reforms are not likely to ease this situation. Innovative approaches such as action learning and action research will only survive in their early days by virtue of huge amounts of energy and enthusiasm from the 'champions for change'.

Despite all these hurdles, developing this program has been an exciting experience for the authors and has brought recognition to SCU as one of the key centres of action research in the world. For the candidates who have completed the program successfully it has resulted in their becoming more reflective managers and, for some, opened up new opportunities in life as in the case of the four managers who originally conceived the program.

One of the highlights of the program is the blending of action learning with action research that has resulted in both research and learning outcomes. The 'learning sets' incorporated in the program design resulted in peer support in Singapore (often an issue with offshore doctoral programs where face-toface contact between the supervisor and the candidate is infrequent). The 'learning set' helped to act as a catalyst to keep the energy and motivation of the candidates going between the times they met their university supervisors. Some of the managers in the program designed their 'core action research projects' to be 'action learning' projects in the two cycle model they adopted from Perry and ZuberSkerritt (1992) to conduct their research as shown in Figure 2.

(Insert Figure 2 about here) 
A majority of the candidates added a 'personal learning' chapter to their thesis explaining how the critical reflection processes they used in action research and action learning changed them as well. This has also been pointed out by Bourner (Bourner and Simpson 2005) in his paper about practitioner centred research and the $\mathrm{PhD}$ in this journal.

For readers of this journal I think that the 'added value' of action learning both within the programme and for the authors as they developed the programme, should be brought out in your final discussion.

\section{References}

AREOL (2006). 'Section 1: Applications', Action Research and Evaluation Online, available at http://www.scu.edu.au/schools/gcm/ar/areol/areol-session01.html

Bourner, T. and Simpson, P. (2005), 'Practitioner-centred research and the PhD.', Action Learning: Research and Practice, 2(2), 133-151.

Checkland, P. (1999) Systems Thinking, Systems Practice (Chichester: Wiley).

Dick, B. (2002) Action research: action and research, available at http://www.scu.edu.au/schools/ gcm/ar/arp/aandr.html

McGill, I. \& Beatty, L. (2001) Action Learning: A Practitioner's Guide, $2^{\text {nd }}$ edn (London, Kogan

Page).

Pedler, M. (ed.) (1997) Action Learning in Practice, $3^{\text {rd }}$ ed. (Aldershot, Gower).

Perry, C. and Zuber-Skerritt., 1992, Action Research in Graduate Management Programs, Higher Education, 23(2), 195-208.

Reason, P. (1999) Integrating action and reflection through cooperative inquiry, Management Learning, 30(2), 207-226.

Sankaran, S., Dick, B., Passfield, R. \& Swepson, P. (eds) (2001) Effective Change Management Using Action Learning and Action Research: Concepts, Frameworks, Processes and Applications, (Lismore, SCU Press).

Sankaran, S. (1997). Memos to myself: A tool to improve reflection during an action research project, available at www.scu.edu.au/schools/gcm/ar/arr/arow/rshankar.html

Sankaran, S (2005), Notes from the field: action research conversations, Action Research, vol. 3, no. 4, pp. 341-52.

Speedy, S. (ed.) (2002) Women Using Action Learning \& Action Research: The South African Context, (Lismore, Southern Cross University Press).

Torbert, W.R. (1991) The Power of Balance: Transforming Self, Society, and Scientific Inquiry, (Newbury Park, Sage).

Yee, A.H. (ed.) (1995) East Asian Higher Education: Traditions and Transformations (Oxford: Pergamon).

Abbreviations used frequently in this paper:

ALARPM - Action Learning, Action Research and Process Management Association of Australia

AREOL - Action Research and Evaluation Online

MaLAR - Management Learning and Action Research

SCPii - Southern Cross Professional Institute International

SCU - Southern Cross University

Note: The authors would like to thank Dr. Tay Boon Hou, Dr. Allan Chung, Dr. Eric Goh, Dr. Radika Vasudev and Dr. Keith Ng for sharing their reflections about being part of the PhD program described in this paper and also acknowledge their permission to using their names. The authors would also like to acknowledge the contribution of Gita Sankaran, who manages the GCM publications project at Southern Cross University, for critically reviewing this paper and copy editing it. (and a comment about permission for the use of names)

Shankar Sankaran is an engineer by background. His areas of research interest are action research, knowledge management and project management. He is the Director of the College of Action Research at SCU and the National Vice President of ALARPM. Shankar uses action learning for leadership development in industry. Email: shankar.sankaran@scu.edu.au

Stewart Hase is a psychologist with an interest in work, and work and learning. He is fascinated by processes within organisations and particularly by expressions of intrapsychic phenomena and how to 
use psychotherapeutic methods to address them. Stewart is the Director of the Southern Cross Institute of Action Research and acting Director of the Graduate College of Management at SCU. Email: stewart.hase@scu.edu.au

Bob Dick helps people and organisations to change, using action learning and action research. Bob facilitates the Action Research and Evaluation On Line (AREOL) course, which is offered as a public service by $\underline{\mathrm{SCU}}$ and administers the action research discussion list arlist. Email: bd@uqconnect.net

Emeritus Professor Alan Davies has retired from Southern Cross University, Australia, but maintains contact with past colleagues and students. He continues to do consulting work running large group intervention processes in organisations and communities. Email: atdavies@bigpond.com 


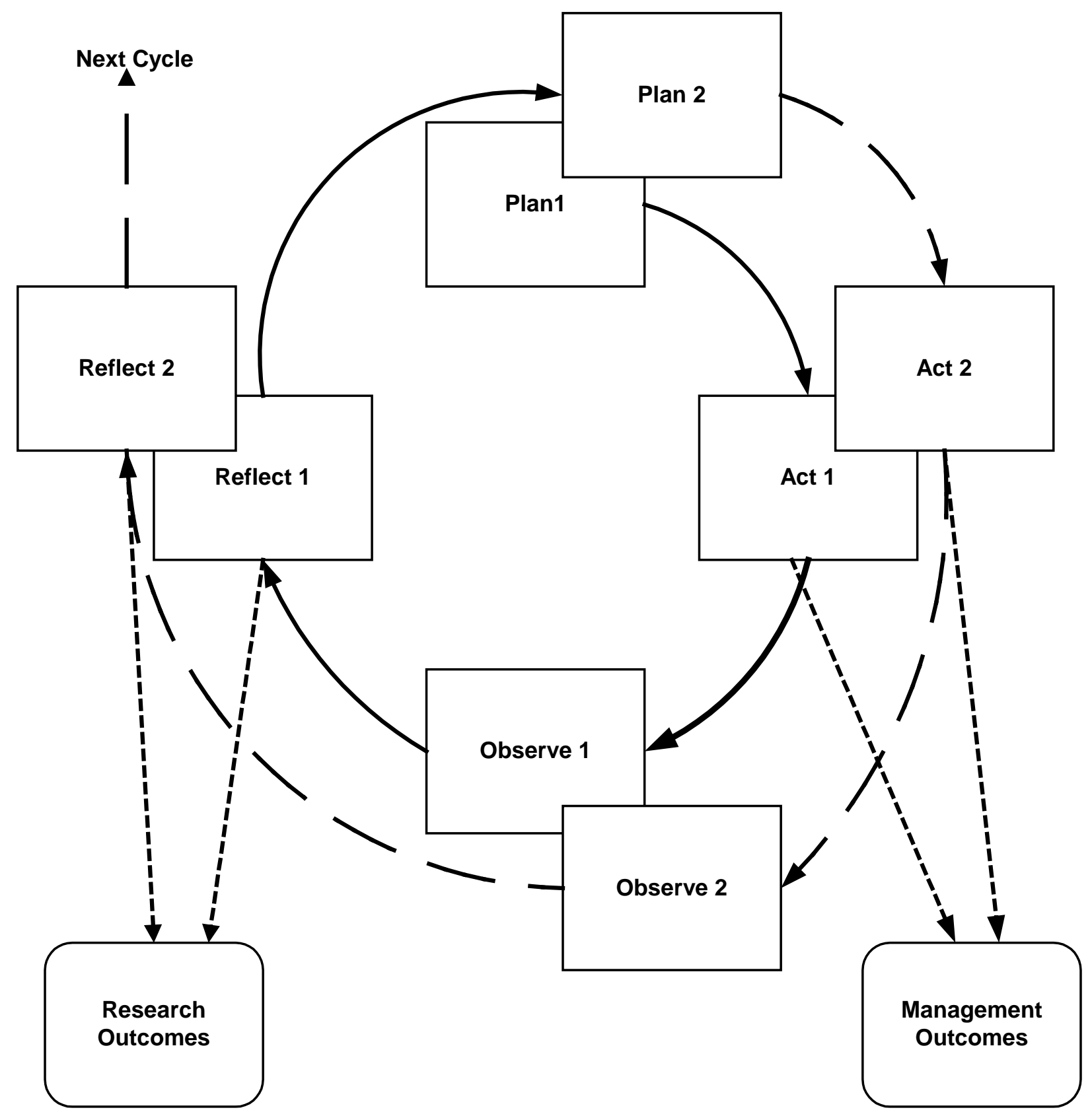

Figure 1 - Management and Research Outcomes 


\section{Core Action Learning Project (s)}

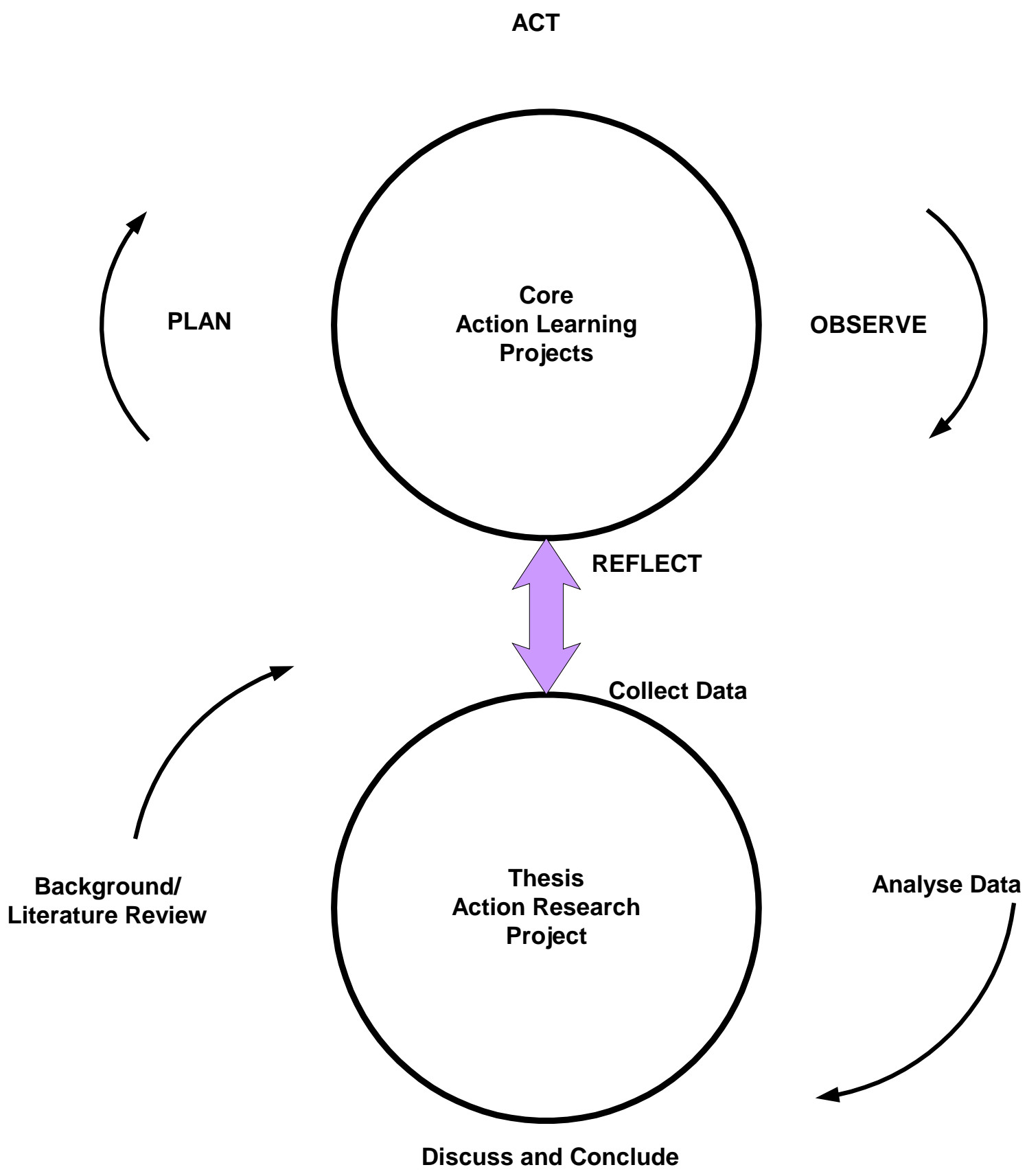

Figure 2 - Combining Action Research and Action Learning

Adapted from Perry and Zuber-Skerritt (1992: 195-208) 